\title{
Research on Innovation of Ding Porcelain Products Based on Intangible Cultural Heritage Technology
}

\author{
Xiaoshu Deng ${ }^{1, *}$ Xiaoqing $\mathrm{Yao}^{2}$, Jing $\mathrm{Liu}^{3}$
}

\author{
${ }^{1}$ North China Electric Power University \\ ${ }^{2}$ North China Electric Power University \\ ${ }^{3}$ North China Electric Power University \\ *Xiaoshu Deng. Email: shu106dxs@126.com
}

\begin{abstract}
The inheritance and development of intangible cultural heritage has always been an important subject. This paper starts from the problems facing the intangible cultural heritage industry, takes the Ding Porcelain as the research object, sorts out its origin and characteristics, puts forward specific innovation strategies for the product development of enterprises according to the current situation of industrial development.
\end{abstract}

Keywords: Intangible cultural heritage technology, Ding Porcelain, Product innovation, Strategy

\section{ORIGIN AND CHARACTERISTICS}

Intangible cultural heritage is a precious treasure of mankind, and its inheritance and development have attracted much attention in recent years. However, at the present stage, the intangible cultural heritage industry is faced with such difficulties as insufficient brand construction, lack of reserve talents, and do not adapt to the new production and sales mode, posing challenges to the development of the industry.

Ding Porcelain began in the Tang Dynasty and reached its peak in the Northern Song Dynasty. Together with $\mathrm{Ru}$, Guan, Ge and Jun, it was named as the five famous porcelain of the Song Dynasty, playing a very important role in the history of Chinese ceramics. Due to its origin in today's Quyang, Hebei, and in the Song Dynasty it belongs to Dingzhou, so named "Ding Porcelain" [1].

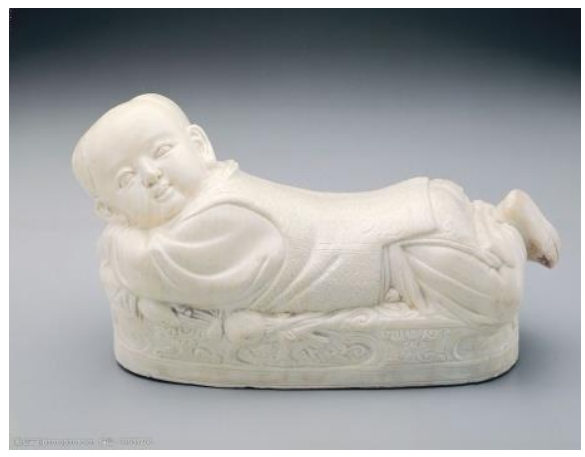

Figure 1 Pillow of Ding Kiln
"Ding Kiln firing technology" is a national intangible cultural heritage, its unique technology is its representative symbol, has a high degree of recognition in the market. The porcelain is thin, light, hard, white, warm and smooth as jade. Ding Porcelain is one of the representatives of white porcelain which is favored by people for its abundant pattern decoration. The decoration techniques include printing, engraving, scratching etc [2]. The composition of the product is simple, the pattern is vivid and natural, giving a feeling of neat and elegant.

\section{DEVELOPMENT STATUS}

Ceramics production in China has a long history, after a long period of development, the manufacturing process has been constantly improved. With the development of society and the improvement of people's living standard, the application of ceramic products in daily life is more and more extensive, and the economic strength and influence of China's ceramic industry are also growing constantly.

However, the brand awareness of domestic enterprises started late, brand management is relatively weak. The development of some kilns is also faced with a series of problems such as design transformation, market followup and brand management. The advantages of Chinese ceramics lie in the profound cultural deposits and the accumulation of exquisite skills, but there is still much room for improvement in marketing and branding development [3]. 


\section{PRODUCT RESEARCH}

\subsection{Product Market Positioning}

Product development can be carried out based on the intangible heritage property and regional culture of Ding Porcelain, specifically from the following aspects:

\subsubsection{Hand-made Emotional Products}

After decades of exploration and technology in the process of recovery, Ding Porcelain has formed some particular handmade symbol, such as printing, engraving, scratching etc. Compared to the products of mass production, these craft technique has a unique sense of temperature. Through the combination of modern design techniques and traditional technology, products can not only retain the characteristics of handwork but also conform to the modern taste and aesthetic.

\subsubsection{Regional Gifts}

The historical background of Ding Porcelain makes it a very representative product in Hebei and even in the whole country, and occupies an important position in the regional gifts. Through the unremitting efforts of Chen Wenzeng and many other masters, Ding Porcelain have reached the advanced level in the field, and it has also become the leader in the regional industry [4]. Product innovation can fully rely on such advantages, and at the same time integrate practicality and fashion to help create new gifts with regional characteristics.

\subsubsection{Cultural Gifts}

With its special material and natural style, Ding Porcelain is full of spirit of culture, which makes it neat and elegant. It has been regarded as the treasure of ceramic art. Ding Porcelain is of the same origin with the quintessence of Chinese traditional culture, such as sculpture, painting, poetry, calligraphy and opera, which can be borrowed from each other. The product development can fully combine the artistic and cultural characteristics of Ding Porcelain, excavate modern practical situation and good implication, carry out innovative design of multiple categories, and make the product become a modern cultural gift.

\subsection{Target Audience}

With the development of society and the improvement of people's living standard, consumers' demand for products has been not only satisfied with the material level, but also the pursuit of the spiritual level. The customer groups of Ding Porcelain are widely distributed, which can be summarized as follows:

\subsubsection{Collectors And Fans}

This group has a comprehensive understanding of Ding Porcelain. They have a professional knowledge of manufacturing process, and strict requirements on the artistic value and quality of products. They have a stronger cognition and emotion of Ding Porcelain. For such a user community, products need to be of high quality and high artistic sense. Therefore, quality should be strictly controlled in the development of new products to guarantee high-quality design value.

\subsubsection{Enterprise Users}

Enterprise customization has higher and higher requirements on practicality and aesthetics of products. Such customers' requirements on quality and design effect are higher than those on price, and additional requirements may occur. Therefore, a variety of customization methods are provided for such customers, and different solutions are provided from simple to complex, so as to meet diverse needs. Customized products are ideal customers for sales without having to worry about inventory and overstock.

\subsubsection{Giver}

Etiquette culture is a part of Chinese traditional culture, the process of reciprocity is actually to send blessings. The uniqueness, artistry and regional nature of Ding Porcelain and, more importantly, its historical culture make it an innate gift. The people who need to give gifts will be the majority of potential users.

\subsubsection{Tourists}

As a tourist province, Hebei is still short of highquality tourist souvenirs. The products of the Ding Porcelain have both regional characteristics and cultural heritage, making it the first choice for tourist souvenirs. In the development process, it is necessary to take into account the portability, practicality and commemorative value, and develop portable, fashionable and artistic products.

\subsection{Product Innovation Strategy}

As representative of people's Congress and the inheritor of Ding Porcelain craft, Pang Yonghui talked about the inheritance and development of Ding Porcelain. He believed that only by integrating the aesthetic concept, spiritual demand, modern technology and innovative design into the development of ceramics could it achieve considerable development [5]. Therefore, we summarize the following product innovation strategies: the excavation of cultural deposits, the product that conforms to modern lifestyle and emotional expression of traditional skills. 


\subsubsection{Excavation Of Cultural Deposits}

The word "Ding"means "must be" in Chinese. We often use it to describe "we will succeed", "we will win" in daily life. Therefore, we proposed to explore the cultural connotation with "Ding culture" as the main body, inherit the cultural stories behind each product. It is not only to design the appearance of the product, but also to highlight the profound cultural heritage. Modern design techniques are adopted to shape the image of the new porcelain products, inject new vitality into the traditional art, and let the culture naturally blend into people's daily life.

\subsubsection{Conforms To Modern Lifestyle}

Ding Porcelain has a long history and mature production process. Its texture is especially clear against the glaze, which has high artistic value. However, with the development of society, people's life style is also changing constantly. It is a major innovation to design daily-used porcelain based on traditional skills to meet the modern use and aesthetic needs. The shape of the product inherits the characteristics of the traditional Ding porcelain with light body, fine and smooth surface, and slightly shining yellow in white. Through modern design techniques and thinking, it provides more possibilities for the product and gives the shape a unique meaning from the perspective of cultural experience.

\subsubsection{Emotional Expression Of Traditional Skills}

Ding Porcelain has engraving, scratching, printing and other processing techniques, these handmade traces are the source of the product's traditional culture flavor. We emotionalize traditional skills. For example, there is a special technique called "Knife Beating", when trimming is finished, special knife is used to gently stroke the wall, the tool and the wall contact with the rotation speed produces a subtle pulsating, forming a kind of rhythmic knife cutting marks of different sizes and different depths [6]. The visual effect formed by this technique is quite beautiful and hazy. We can make an emotional connection with the effect in the design, so as to make it jump out of the category of a craft technique and transform it into an expression of artistic conception.

\subsection{Marketing Strategy}

A good marketing strategy will increase the market competitiveness of a good product [7]. Combined with research and practice, we believe that the marketing of Ding Porcelain products can be carried out from the following aspects:

\subsubsection{National Gift}

Like silk and tea, Chinese porcelain had a great influence on the world. Ding Porcelain is one of the five famous porcelain, with a history of nearly a thousand years. It used to be the imperial porcelain. Both the Palace Museum and the National Museum have fine collections of porcelain [8]. Its historical and cultural attributes are enough to bear the "national gift". National gift not only represent status, but also represent high quality and high value.

\subsubsection{Auspicious Culture}

It is a common technique to apply various patterns on ceramic products. These patterns have meanings and the meanings must also be auspicious, representing people's longing for a better life. Although times are developing and changing, people's vision of a better life remains the same. In the process of product marketing, we can excavate culture and implication, deeply study consumer psychology and user demand, and integrate the culture of auspiciousness into it.

\subsubsection{Healthy Life}

Currently novel Corona-virus crisis has affected the world and people are paying increasing attention to healthy life. The Ding Porcelain is fired at high temperature from the local natural raw ore, and the glaze is composed of quartz, kaolin, limestone and other natural minerals, without adding any chemical raw materials or oxide colorant. The safety and environmental protection data far exceeds the national standard. Ding Porcelain is fired at high temperature, so the product has high sintering, low water absorption, no residue and easy cleaning of tea stains, etc. All kinds of characteristics are closely related to the healthy life of consumers, and we believe that it is the hot spot of future market consumption.

\section{EXTENDED APPLICATION OF DING PORCELAIN}

The existing products of Ding Porcelain are mainly traditional tea sets, decorations and tableware. The category is relatively limited, but the development potential is huge. The development of the existing market can refer to the following directions:

\subsection{Fashion Item}

The existing consumer groups of Ding Porcelain are mostly middle-aged and old people, while young people have little cognition. On the one hand, the reason is the lack of product categories, and on the other hand, the high price.We can launch online products with high cost performance for young groups, integrate fashion 
elements, create new visual forms, and guide the aesthetic trend of young groups.

\subsection{Household Products}

Ding Porcelain has the characteristics of wear resistance, easy to clean, no deformation, no fading. It has an artistic effect that no other material can match.Combining Ding Porcelain with the design of household articles can reflect the advantages and practical value of ceramics.

\section{PRODUCT DESIGN PRACTICE}

Ceramics are the crystallization of Chinese traditional culture. Ding Kiln is famous all over the world for firing white porcelain. They have intangible cultural heritage technology as the basis for product innovation to provide technical support. On the basis of the preliminary study, we take the numerous students as the target users, integrate auspicious culture into product modeling and design the following product.

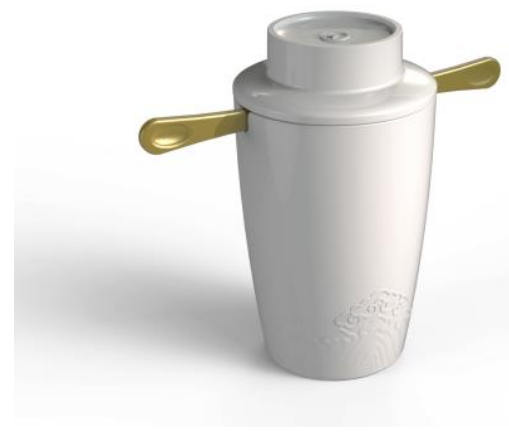

Figure 2 In U R (Patented Product)

In $\mathrm{U} R$ is a cup produced by Ding Kiln, its inspiration is top-scorer's hat. As a cup, the product represents the examinee. The process of holding water in the cup symbolizes the process of enriching students' knowledge. They enrich themselves, and make their dream come true.

The design on the body of the cup is like the sea water rushing forward, implying that students can achieve success. Different combinations of the cup can form a Chinese character "Ding", for example, the stirring rod and cup, which means to be sure that the examinee can successfully pass the exam. The stirrer rod can be placed on the lid, ensuring its cleanliness.

\section{CONCLUSION}

Design is an indispensable innovation gene [9]. This research aims at the inheritance and innovative application of intangible cultural heritage technology, bases on the deep cultural heritage of the Ding Porcelain technology. It explores consumers' needs for use, integrates modern design concepts, and develop the serialization and branding of daily porcelain on the basis of Ding culture. In doing so, it can help the development of intangible cultural Heritage, practice the deep integration of design and traditional cultural industry, and realize the dual benefits of cultural inheritance and economic benefits [10].

\section{ACKNOWLEDGMENTS}

This paper is the result of General Project of Basic Scientific Research in Central Universities. Project name is "General Education on Design of Building First-class Universities", and project number is 2019MS149. Thanks for the support.

\section{REFERENCES}

[1] The Palace Museum, Collection of Ding Porcelain: A collection of Ding porcelain from the Palace Museum, in: Palace Museum Press, Beijing, China.

[2] Yang Jiaying, Zhang Ting, Zhou Meiyan, Research on innovative design of ceramic products based on Song Dynasty imperial kilns, in: Home of Drama,181-182.

[3] Deng Long, Li Hongle, The fusion and innovation of traditional ceramic art and modern product design, in: Ceramics Science \& Art,6-7.

[4] Han Qingfang, Chinese Arts and Crafts master Chen Wenzeng (Ding Porcelain), in: Jiangsu Fine Arts Publishing House, Nanjing, Jiangsu, China.

[5] Pang Yonghui, Promote the innovative development of intangible cultural heritage industries and consolidate achievements in poverty alleviation,DOI:http://www.xinhuanet.com/politics/ 2020lh/2020-05/27/c_139091656.htm

[6] Han Qingfang, Chinese Arts and Crafts master Chen Wenzeng (Ding Porcelain), in: Jiangsu Fine Arts Publishing House, Nanjing, Jiangsu, China.

[7] You Lanlan, Influence of the concept of art and life on the innovative design of Liling Porcelain Products, in: Modern decoration (Theory), 138 .

[8] Pang Yonghui, Unswerving Inheritance. DOI:http://www.xinhuanet.com/video/202006/13/c_1210659702.htm

[9] He Jing, Research on the innovative design method of modern tea set product modeling, in: Journal of Jingdezhen College,76-79.

[10] Tong Yi, Innovative practice of regional intangible cultural heritage elements in art design major teaching, in: Higher Education, 105. 